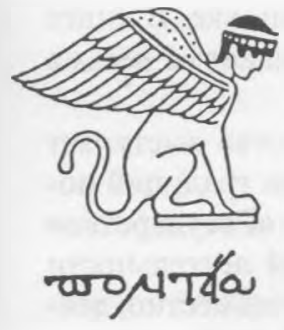

* Ханна Аренотm. Vita Activa, uлu o деятельной жизн. Издательство "Aлетейr", СПб, $2000,437 c$

\section{Oт «Иетекев} тоталитаризма» к «Vifa aetiva»

' Aрендт X. Истоки тоталитаризла. M., 1996.

${ }^{2}$ CM. Canovan $M$. Hannah Arendt: $A$ Reinterpretation of Her Personal Thought. N.Y., 1992.
Когда Ханна Арендт (1906-1975) называла свои исследования политической публицистикой с опорой на историю, или политической экономией, она со свойственной ей скромностью сужала сферу своей многоплановой научной и публицистической деятельности. Ее с полным правом можно назвать философом, политологом, социологом, историком и культурологом, ибо таковы еще далеко не все грани ее творчества.

Одним из фундаментальных научных исследований Арендт стала ее книга «Истоки тоталитаризма», опубликованная в 1951 г. ${ }^{1}$ Работа представляла собой попытку теоретического осмысления тоталитаризма, условий, порождающих тоталитарный тип власти. Книга «Vita activa» посвящена анализу фундаментальных для современной философии и политологии проблем: влиянию современной научно-технической революции на бытие человека, столкновению между нравственностью и политикой, действием и созерцанием, политикой и философией².

Как следует из названия книги Х. Арендт, речь в ней идет о vita activa, или деятельной жизни, которая, по мысли автора, охватывает три основных аспекта человеческой деятельности: труд (работу), создание (изготовление) и действие (поступки). Последнее единственный вид деятельности в vita activa, которая развертывается без посредства материи и материалов прямо между людьми.

Тему книги можно определить одной немудреной фразой, позаимствованной из самой же работы: «Я предлагаю что-то очень простое, дело для меня не идет ни о чем другом, кроме продумывания того, что мы собственно делаем, когда мы деятельны» (с. 12-13). Несколько ниже эта мысль выглядит совсем лаконично: «Что мы делаем, когда мы заняты активной деятельностью» (c. 13). Как пытливый патологоанатом, раскладывающий по косточкам человеческое тело, так Ханна Арендт скрупулезно рассматривала части и частички человеческой деятельности, правда, coзнательно отказываясь от исследования деятельности мысли (vita contemplativa).

Структура книги сосредоточена вокруг трех тем: труд (работа), создание (изготовление) и действие (поступки). По замыслу Арендт, исторический горизонт книги ограничен концом Нового 
времени, хотя автор строго и не следует этой установке. В книге явно и неявно присутствует современность, что делает её весьма актуальной для нашего времени.

Автор «Истоков тоталитаризма» и в «Vita activa» выступает как глубокий и тонкий политолог. Она - наследница традиций политической мысли, уходящей своими корнями в «Государство» Платона. Согласно Арендт, все виды человеческой деятельности обусловлены тем обстоятельством, что люди живут совместно; действие не представимо вне человеческого общества, вне политики. Останавливаясь на отношении к активной деятельности в античности и разбирая определение человека Аристотелем как существа политического, Арендт замечала, что в ту эпоху «никакой деятельности, служашей лишь цели жизнеобеспечения и поддержания жизненного процесса, не было дозволено появляться в политическом пространстве» (с. 49). И еще один сугубо политологический аспект книги - вывод автора: там, где политика занята только лишь властью, одной лишь властью, она может обернуться чем угодно, но только не свободой, законностью и демократией.

B «Vita activa», как и в некоторых других работах Арендт, образцами политической жизни, в которой равные в свободе индивиды отдают. себя служению общественному благу, служат греческий полис и городские общины Новой Англии периода борьбы американцев за свою независимость, а также Советы в России (до их бюрократического перерождения) и в Венгрии периода ре-

${ }^{3}$ См. Антология политической мbцли в пати томах. T.11. M., 1997 c. 524 . волюционных событий 1956 г. $^{3}$

Предлагаемое Арендт различие между трудом (работой) и созданием (изготовлением) непривычно, особенно если не быть знакомым с понятиями Локка: «создаюшие» руки и «трудяшиеся» тела: так, собственно, и называется один из параграфов книги: «Труд наших тел и создание наших рук». Классическая античность как бы игнорировала это различение. Новоевропейское понимание, уже на своей начальной стадии, обнаруживает несходство между производительным и непроизводительным трудом, а позднее - между трудом квалифицированным и неквалифицированным. Арендт полагала, что принципиальное несоответствие между трудом и созданием уже содержится в различении между производительным и непроизводительным трудом. «В самом деле, - писала она, - отличительная черта труда состоит именно в том, что он не оставляет по себе ничего объективно осязаемого, результат его усилий сразу снова потребляется и очень недолговечен». И тем не менее, продолжала автор, «перед лицом беспримерного взлета производительности в новоевропейском обществе дело было близко к тому, чтобы списать «непроизводительный» труд, всегда остающийся одинаковым, на счет остаточного явления из прошлых времен и приписать труду качества, присущие только изготовлению, заговорив о трудящемся животном, animal laborans так, как если бы он был по своей собственной сути homo faber» (c. 112-113). 
Действие невозможно в изоляции: всякая изоляция (вольная или невольная) лишает способности поступать. Точно так же, как изготовление нуждается в природном окружении, снабжающем человека материалом, и в среде, где готовая продукция может продемонстрировать свои достоинства, так и действие, поступок нуждаются в мире людей, чтобы обратиться к нему.

В то время как процесс изготовления, затратив всю свою энергию на конечный продукт, угасает, энергия, расковавшая действие, не умирает в событии. «Что в области дел человеческих продолжает существовать, - отмечала Арендт, - так это раскованные однажды процессы содеянного, и их продление в своих последствиях не имеет границы, будучи ограничено в крайнем случае существованием человечества на земле, но не смертностью людей и не тленностью земной материи» (с. 309). Арендт считала, что процесс, раскованный одним единственным деянием, может в своих последствиях длиться буквально века, а то и тысячелетия, пока человечество не встретит свой последний день.

Арендт нередко повторяла одну мысль: мастерство наших

- Латинское слово faber связано $c$ facere в сиысле «изzотовляючего деланит), оно обозначает ремесленника или художсника, обрабаmьвакоцего тверdoiй мaтерuaл .иеталl, канень, дерево.

рук, а не труд нашего тела (homo faber ${ }^{4}$ ), обрабатывающий тот или иной материал в целях изготовления, а не как жизненную потребность (animal laborans), тесно сливающуюся с материалом своей работы, создает несчетное множество вещей и предметов, сумма которых складывается в мир, выстраиваемый человеком. Те орудия труда, которые служат работающему животному (animal laborans) лишь для облегчения своего бремени и механизации труда, homo faber задумал и изобрел для создания мира вещей (с. 175-185). Изучение различий между трудом (работой) и созданием (изготовлением) привели Арендт к выводу, что в мире произошло извращение средств, ставших целью и, наоборот, целей, превратившихся в средства. Средства оказались сильнее целей, что привело к тому, что человек стал рабом машин, которые он сам же и изобрел, вызвал к жизни.

Арендт убедительно доказывала, что действие требует открытой публичной сферы, где оно при помощи слова, речи сообщает о себе другим для продолжения и запечатления; устанавливается взаимосвязь между смыслом действия и словом. Именно в речи и действии проявляется, по мысли Арендт, своеобразие, уникальность человеческой личности. Говоря и действуя, люди «активно отличают себя друг от друга», причем, функция речи, как полагает автор, не в том, чтобы как-то объяснить действие, - «слово скорее идентифицирует деятеля и объявляет, что действует именно он». Нет другого человеческого установления, в такой же мере нуждающегося в словах, как действие. Действуя и говоря, люди постоянно обнаруживают кто они суть, раскрывают свою индивидуальную неповторимость (c. 233-234). 
Хриетианетво, дегтельная жизиь и Make Be6ep

Немалый интерес в книге представляет трактовка Арендт влияния христианства на отношение к деятельной жизни, к труду. Христианство, считает она, принесло нивелирование старых различий и подразделений внутри vita activa, ибо все они начали в равной мере рассматриваться как деятельность, необходимая для поддержания жизни. Это означало, прежде всего, что христианство покончило с характерным для античности презрительным отношением к физическому труду. Однако, Арендт вступила в полемику с целой когортой интерпретаторов христианства, напрямую связывающих возвеличивание труда с учением Иисуса Христа.

Исследуя работы многих христианских мыслителей с точки зрения их отношения к активной деятельности, автор приходит к выводу, что труд для них является способом поддержания жизненного существования рода человеческого. С их точки зрения, человек призван работать лишь тогда, когда никак иначе он помочь себе не может. Так, из произведений Фомы Аквинского и некоторых других христианских мыслителей, монастырских правил и предписаний следует, что «если можно человеку добыть пропитание нищенством, то тем лучше» (с. 413). Если эти источники читать без современных предрассудков, полагала Арендт, «то диву даешься, как редко Отцам Церкви приходила в голову простая в сущности идея объявить труд наказанием за первородный грех, ссылаясь в этом смысле на слова Павла: «Кто не работает, да не ест». Но Фома Аквинский, например, следует скорее не Ветхому или Новому Завету, а Аристотелю, когда пишет, что лишь только «необходимость принуждает к телесному труду» (с. 413).

Арендт утверждала, что христианская вера в жизнь после смерти, где будущее блаженство дает о себе знать в радости созерцания, как бы узаконивала принижение активной деятельности. Августин, например, в трактате «О граде Божьем» писал о бремени деятельной жизни, которое было бы невыносимо без «сладостного» блаженства созерцания божественной истины.

Призывы трудиться ради искупления вызванных праздностью искушений и грехов имеют, как считала Арендт, вовсе не христианское, а римское происхождение, как и вообще значительная часть христианской нравственности, которая в ее интерпретации оказывается прямой наследницей Древнего Рима. Арендт не голословна. Ее выводы опираются на широкий круг источников (Библия, Фома Аквинский, Августин, монастырские правила бенедиктинцев, доминиканец Бернар Алло и др., а также на работы современных исследователей христианства).

Христианство, полагала Арендт, уже потому не могло развернуть собственную философию труда, что неизменно придерживалось позиции безусловного превосходства созерцательного 
труда над всеми видами деятельности vita activa. Фома Аквинский писал в трактате «Сумма теологии»: «Созерцательная жизнь в абсолютном смысле лучше, чем жизнь деятельная» (c.415). Такое отношение к труду, считала Арендт, заведомо не характерно для воззрений Христа и его последователей, оно стало следствием мощного воздействия греческой философии. «Единственная проповедь Иисуса, - писала автор, - это поступок, и единственная человеческая способность, занимахщая в ней центральное место, это вера, творящая чудеса» (там же).

Решающим в контексте этих рассуждений оказалось то, что Новое время объявило именно жизнь, а не мир земных благ верховной ценностью. Для мыслителей Нового времени очевидным императивом стал примат жизни над всем прочим, который не утратил своей убедительности и в современном мире.

Потрясение христианской веры, считала Арендт, идет вовсе не от атеизма XVIII в. или материализма XIX в., как это принято считать. Аргументация как того, так и другого, «никогда не достигала подлинной глубины мысли, действительно причастной к вере, и которые к тому же поддавались фронтальному опровержению в рамках традиционной теологии» (с. 416). Это потрясение, настаивала автор, вызвано было скорее сомнением, вторгшимся в саму веру, ускорение которому придала Реформация.

Любое мало-мальски серьезное рассмотрение проблем, связанных с отношением христианства к трудовой активности, вряд ли может обойтись без обрашения к работам Макса Вебера, и, прежде всего, к его классической «Протестантской этике и духу

' Вебер М. Избранные произведения. М., Прогресс, 1990.

капитализма» ${ }^{5}$. Арендт отдает должное его блестящим исследованиям, обильно цитирует, часто восхищается ими, внося определенные коррективы в известную теорию Вебера.

В примечании 36 к шестой главе книги Арендт отмечала, что Вебер остается «до сего дня единственным историком, раскрывшим проблематику Нового Времени с адекватной глубиной и релевантностью", точно уловив, что "новая профессиональная и трудовая этика объяснялась не столько утратой веры, сколько утратой чувства достоверности спасения, certitudo salutis». На этом основании Арендт делала весьма важное замечание: «В контексте нашего разбора утрата этой достоверности представляется лишь формой общей утраты достоверности, происшедшей с началом Нового времени» (с. 364), истоки которой лежат не только в религии, Реформации и Контрреформации. «История этих веков, - писала она, - показывает скорее, что утрата веры отбросила людей не к миру и посюсторонности, а наоборот к самим себе» (c. 336). Автор видела значение, или лучше сказать, величие «открытия истоков капитализма» Максом Вебером именно в доказательстве им того, что вполне земная активность людей может происходить из интереса к своей собственной самости и из заботы о спасении

"IOAHTh" №3(21) Осень 2001 
${ }^{-}$CM., ranpurep. речь Карла Ясперса на похоронах Макса Вебера. К.Ясперс. Речь паияти Макса Вебера. Макс Вебер. Избранное. Образ обuecmsa. M., 1994 c. $553-566$.

${ }^{\prime}$ С. Бибихин В. B. Послесловие переводчика, c. $428-429$.

души. С точки зрения Арендт, отчуждение от мира, а не отчуждение от самости (как полагал Маркс), стало характерным признаком Нового времени (с. 336).

На несовпадение взглядов Вебера и Арендт относительно влияния протестантизма обратил внимание Карл Ясперс. Будучи горячим поклонником Вебера ${ }^{6}$ и давним другом Арендт, выдающийся немецкий философ в одном из писем к автору «Vita activa» (от 1 декабря 1960 г.), откликаясь на выход ее книги и высоко оценивая ее автора («Ваши многочисленные конкретные идеи и озарения, историческая глубина обоснований придают всему осязаемую прямую содержательность»), мягко критиковал Арендт именно за вышеприведенный пассаж, который Ясперс цитировал по памяти, а потому не совсем точно: «...Я спотыкаюсь о короткую фразу относительно веберовского кальвинизма: «частично скорректировано». Я хотел бы указания, в чем скорректировано. Как раз эту работу Макса Вебера («Протестантская этика и дух капитализма» - М.Л.) отличает научная утонченность, которую мир улавливает с таким трудом... Этот пункт для меня немаловажен, ибо дело идет о смысле достигнутой Максом Вебером научности. Макс Вебер, вероятно, во многом другом поддается коррекции, если уж пользоваться таким словом, и я тоже, конечно, спорю с ним, как еще и при его жизни. Однако в этой единственной работе (в отличие от прочих религиозно-социологических томов), указывая на ошибки, надо обязательно видеть всю суть дела и повторять за Максом Вебером его познавательные шаги» ${ }^{7}$ К Как видно, Ханна Арендт на этот счет имела иное мнение.

С приходом Нового времени утрата чувства достоверности спасения, с ее точки зрения, утвердилась не только в душах людей, но и «сердце точных наук о природе»; современная физическая картина мира оказалась не только непредставимой, но и неуловимой для понятий и категорий человеческого разума (c. 378). Глубокие перемены, произошедшие в человеческом образе мысли, истоком которых стал XVII в., перевернули традиционный порядок теории и практики, созерцания и действия.

- Новом времени и совренениом mipe
Образ мышления Нового времени, как подчеркивалось выше, резко и контрастно отличается от всей традиции более ранних времен. Новое время особое место отвело homo faber c его исключительным доверием к орудиям производства и высокой оценкой производительности, абсолютизацией категории «цели - средства» и убеждением, что принцип полезности способен разрешить все проблемы и объяснить все человеческие мотивации.

Для человека Нового времени природа становится материалом, она воспринимается (используя слова Анри Бергсона) как «гигантски громадное полотно, из которого мы можем выкраи- 
вать что хотим, чтобы снова перекроить все по нашему желанию» (с. 398-399). Расширив способности homo faber, научив его изготовлять и изобретать, Новое время, вместе с тем, отняло у него «надежные мерки, которые со своей стороны располагаясь по ту сторону процесса изготовления, предоставляли ему подлинный, в самой его деятельности коренящийся доступ к чему-то абсолютному и безусловно надежному» (с. 401). Одним словом, по мнению Арендт, homo faber утратил способность к созерцанию и размышлению как смыслонаделяющую человеческую способность.

Мысли Арендт о современном мире относились, прежде всего, к западному обществу потребления, в котором «внешние признаки необходимости, тяготы и бедствия, почти исчезли». Люди в нем не ощущают (либо ощущают лишь в самой слабой степени) «напор и принуждение необходимости, гонящие и подстегивающие общественную жизнь» (с. 174). Автор подвергала сомнению оптимизм многих исследователей в отношении будущего такого общества, видя опасность в том, что «ослепленное избытком своей возрастаюшей плодовитости и втянутое в гладкое функционирование бесконечного процесса, оно забывает о своей тщетности - об эфемерности жизни, которая, по мысли Адама Смита, «не утверждает и не осуществляет себя ни в каком постоянном субстрате, способном еще существовать, когда трудовое усилие прекратилось»» (с. 174).

С Марксом Арендт сходилась, пожалуй, в одном, наиболее существенном, в том, что целью революции должно стать освобождение человека от труда, от его рабства. Для Арендт, как и для Маркса, освобождение от труда тождественно освобождению от необходимости, от принуждения. Сдвиги последних десятилетий, предшествовавших написанию исследования, свидетельствовали (уже тогда!) о том, что автоматизация с ее необычайными, казавшимися в то время фантастическими, возможностями, может легко превратить вчерашнюю утопию в завтрашнюю реальность, и, как замечала Арендт, «в итоге действительно от всех тягот и трудов, в чей биологический круговорот казалась вовлеченной человеческая жизнь, останется только «усилие» открыть рот, чтобы проглотить еду» (с. 168).

Вглядываясь в будущее, Арендт приходит к выводу, что даже такое осуществление «утопии» принципиально не изменит мира, ибо «великая надежда, воодушевлявшая Маркса и лучших представителей рабочего движения на то, что свободное время избавит, наконец, людей от нужды и animal laborans станет производительным, покоится на иллюзиях механистического мировоззрения, полагающего, что рабочая сила подобно всякой другой энергии никогда не сможет исчезнуть и потому, не растраченная на тяготы жизни и не истощенная, автоматически 
См. подробиее Магун А. Понатие суждения в философии Ханны Арендт. // Bonpocы философии. 1998. №11

C. $1 / 2$. высвободится для “высшего"» (с. 171). Арендт полагала, что когда Маркс выдвигал эти идеи, перед его глазами стояла модель Афин времен Перикла; в то время лучшие умы считали, что на основе невероятно возросшей производительности труда можно обойтись без труда рабов. Во время написания «Viva activa» ложность таких умозаключений стала очевидной. Animal laborans не тратит свое избыточное время ни на что другое, кроме потребления, и чем больше ему будет предоставлено свободного времени, тем ненасытней и опасней станут его желания, тем больше возрастет его аппетит. «В итоге, - предрекала автор, - все предметы мира, так называемые предметы культуры наряду с объектами потребления, падут жертвой пожирания и уничтожения» (c. 171). Для Арендт зловеще выглядит массовое благосостояние без благодатного труда тела, без вдумчивого усердия художника-изготовителя, без простора ответственного поступка ${ }^{8}$.

Утешением (хотя и слабым) служит лишь то, что мы находимся на ранней стадии этого процесса, однако достаточно зримым признаком надвигающейся беды стал феномен, именуемый «массовой культурой», когда «культуру применяют, злоупотребляя ею и потребительски истощая ее, для развлечения масс, которым надо убить время» (с. 172). Подобные мысли роднят Арендт с идеями О. Шпенглера, который во внедрении и распространении «массовой культуры» видел один из явных признаков надвигающегося «заката Европы». B «Vita activa» Арендт фактически продолжала развивать традицию критики «массового общества», наметившуюся в творчестве позднего Ницше, и подхваченную впоследствии Ясперсом.

Будущее пугало Арендт размывающимся равновесием между трудом и потреблением, между деятельным бытием и покоем. Современная экономика с огромной скоростью движется в направлении так называемой waste economy, хозяйствования с опорой на растрату, где во всяком предмете видят бросовый товар и расходуют, и выбрасывают вещи почти сразу же после их появления на свет, поскольку иначе весь сложнейший процесс производства закончится внезапной катастрофой (с. 173).

Мир же, в котором мы живем, по мысли Арендт, состоит вовсе не из продуктов, подлежащих потреблению и поглощению, а из предметов и вещей, подлежащих использованию и употреблению. Для animal laborans (Арендт явно отдавала предпочтение именно этому типу труда) природа, земля - благодать, которая сыплет как из рога изобилия «блага», принадлежашие всем детям земли; но природа перестает быть дарительницей, когда бывший animal laborans, превратившийся в homo faber, берется за построение своего неестественного, искусственного мира.

To, что в современном мире вновь утверждается animal laborans (человек пришел к тому, с чего и начал), Арендт объясняла не 
в последнюю очередь явлением, которое обычно называют обмирщением или секуляризацией. «Жизнь индивида снова стала смертной, такой же, какой она была в античности, но мир, в каком отныне движутся смертные...стал даже более шатким и ненадежным, чем был когда-либо в века еще не поколебленной христианской веры» (с. 417)».

Сравнения современного мира с прошедшими временами привели Арендт к мысли, что в наш век наблюдается громадная «убыль опыта». С ее точки зрения, не только созерцательность не находит места в системе человеческого опыта, но и сама мысль деградирует, замещаясь электронными счетными машинами. В современном обществе все зримей проявляется неподвластность людям перекроенного ими же самими на свой лад мира.

Наступило время, когда мир оказался нацеленным исключительно на трудовую деятельность, когда из жизненного процесса оказалась исключена присущая труду мучительная тягость. На своей последней стадии трудовой социум превращается в социум обладателей рабочего места (jobholders), от которых не требуется ничего, кроме автоматического функционирования.

Прогнозы Арендт весьма пессимистичны. Хотя человек пока еще не утратил функций создания, изготовления и производства, его созидательные способности становятся все более ограниченными. «Вполне мыслимо, что Новое время, начавшееся такой неслыханной и неслыханно обещающей активизацией всех человеческих способностей и деятельностей, завершится в конечном счете самой мертвенной, самой стерильной пассивностью, какую когда-либо знала история» (с. 420).

Все эти рассуждения Арендт не имеют отношения к работе человеческой мысли (автор не останавливается или почти не останавливается на этой проблеме), исходя, видимо, из того, что ни одна традиция, включая Новое время, никогда не понимала работу мысли в качестве деятельности внутри vita activa.

С Арендт трудно во всем согласиться, с ней нередко хочется спорить, и не только по частным вопросам. Не убеждает, например, авторское разграничение трудовых навыков тела от ремесленно-художественного творчества, отделение политического действия от законодательства и т.д. Но это все детали. Главное совсем не в том, что Аренд порой неточна и сбивчива. Гораздо важнее то, что ее книга располагает к раздумьям над многими глобальными проблемами, которым автор дает свою, как правило, интересную, нестандартную трактовку.

«Vita activa» Ханны Арендт - обобщающее исследование о деятельной жизни человека на протяжении нескольких тысячелетий. Автор книги не связывает себя с каким бы то ни было политическим течением, в этом смысле Арендт абсолютно не ангажирована. История человечества представляется ей сплошным 
- CM. Wolin $S$. Hannah Arendt and the ordinance of Time. - Social Research 44 (1997),

процессом отчуждения от мира. Автор - профессионал высочайшего класса, которого отличает глубокое проникновение в суть предмета исследования. «Труд - работа - действие», как и некоторые другие основополагающие для данной работы понятия внесли новый элемент в традиционные категории академической политической науки'.

При всей скрупулезности и строгой научности постановки проблем, книга написана мастерской рукой человека, явно обладавшего литературными способностями. Автор не упрошает проблемы, но и не «утяжеляет» их; последнее иной раз свойственно мыслителям, особенно немецкой школы философии, к которым Арендт, несомненно, принадлежит. Работа насыщена, может быть, даже перенасыщена идеями как самого автора, так и ее предшественников, со многими из которых она жарко спорит. Исследуя сложные, глубинные процессы, Арендт (что бывает далеко не всегда) озабочена и тем, чтобы ее понял образованный читатель, более того, увлекся ходом ее мысли. Свободная от банальностей, книга Арендт насыщена новыми, оригинальными подходами к, казалось бы, ясным и давно разрешенным в литературе вопросам. 